\title{
MULTIVARIATE PRINCIPAL COMPONENT ANALYSIS OF THE MORPHOMETRIC TRAITS OF SOME CATTLE BREEDS IN NIGERIA
}

\author{
A. Yakubu ${ }^{1 *}$, A-R., Abdullah ${ }^{2 * *}$, A.O. Raji ${ }^{3}$ and S.O. Oseni ${ }^{4}$ \\ ${ }^{1}$ Department of Animal Science, Faculty of Agriculture, Nasarawa State University, Keffi, Shabu-Lafia Campus, P.M.B. \\ 135, Lafia, Nasarawa State, Nigeria. \\ ${ }^{2}$ Department of Animal Science, School of Agriculture and Industrial Technology, Babcock University, Ilishan Remo, \\ P.M.B. 21244, Lagos State, Nigeria. \\ ${ }^{3}$ Department of Animal Science, Faculty of Agriculture, University of Maiduguri, Maiduguri, Nigeria. \\ ${ }^{4}$ Department of Animal Science, Faculty of Agriculture, Obafemi Awolowo University, Ile-Ife, Nigeria. \\ *,**Corresponding Authors' Email: abdulmojyak@gmail.com; abdulkubu@nsuk.edu.ng; arabdullah2002@yahoo.co.uk
}

\begin{abstract}
The conservation of Nigerian cattle is of increasing concern because of their historical and genetic value. Phenotypic characterization involves the differentiation of groups and/or breeds and provides support for conservation programmes. In this study, we reported quantitative examination of four Nigerian cattle breeds using multivariate technique. Data were collected from a total of 2,120 randomly selected trade cattle of both sexes (1,008 males and 1,112 females) comprising 859 Bunaji, 674 Sokoto Gudali, 409 Rahaji and 178 Kuri transported from the northern parts to the south western part of the country for sale. The animals were divided into four ages viz., 2-tooth, 4-tooth, 6-tooth and 8-tooth ages, respectively based on the eruption of permanent incisors. Eight biometric traits were taken on each animal namely height at withers (HTW), height at shoulders (HTS), body length (BDL), shoulder to tail drop (STD), heart girth (HTG), cannon circumference (CNC), ear length (ERL) and tail length (TLL). The fixed effects of breed, sex and age including their interactions on body traits were tested using General linear model (GLM). Pearson's coefficients of correlation among the various linear body measurements were computed. The multivariate approach involved the use of principal component $(\mathrm{PC})$ analysis. Based on univariate analysis, the Kuri cattle had significantly $(\mathrm{P}<0.05)$ higher morphometric variables compared to other breeds. Sex and age also influenced $(\mathrm{P}<0.05)$ all the body parameters while there were breed and sex; breed and age; sex and age; and breed and sex and age interaction effects on the body traits. Phenotypic correlation Coefficients among the traits were positive and significant $(\mathrm{P}<0.01)$, ranging from 0.13-0.92. In the PC analysis, two parameters (STD and HTS) were sufficient for breed differentiation based on eigenvalue lower than 0.7. The present information may be useful for animal evaluation and when complemented with molecular diversity analysis, could be exploited in future efforts aimed at conserving the indigenous cattle.
\end{abstract}

Keywords: Morphological traits, multivariate analysis, diversity, cattle, Nigeria.

https://doi.org/10.36899/JAPS.2021.3.0258

Published online November 09,2020

\section{INTRODUCTION}

There are very diverse livestock breeds that are adapted to a wide variety of environments as a result of domestication, breed formation and selection schemes. Such locally adapted or indigenous breeds with special characteristics are usually owned by rural farmers (Rege et al., 2011). The indigenous livestock breeds are indispensable to rural farmers and produce a wider range of products. They could also be managed under low forage and health management and are more sustainable ecologically, especially in marginal environments (Kohler-Röllefson, 2000; Rege et al., 2011; Aksoy et al., 2018). There exists enormous intra- and inter-group variability in productive, morphological and adaptive traits of cattle breeds (The Bovine HapMap Consortium, 2009; Mustapha et al., 2018; Ladyka et al., 2020). Despite the identification of most indigenous African breeds of cattle, majority of them remain largely uncharacterized phenotypically and molecularly (Nyamushamba et al., 2017).

External appearance (morphology) is still commonly used by researchers and practitioners in the identification, characterization and selection of farm animals (Mwacharo et al., 2006; Sobczuk and Komosa, 2012; Houessou et al., 2019). Linear body measurements and indices are useful to assess type and function in cattle (Schwabe and Hall, 1989). Phenotypic and genetic relationships among biometric traits of animals have involved the use of analysis of variance and correlation (Dietl et al., 2005; Tolenkhomba et al., 2013; Vohra et al., 2015). However, there might be difference in biological relationship existing among the linear body variates if these body measurements are treated as bivariates rather than multivariates (Yakubu et al., 2011a and b; Kern et al., 2014). An alternative approach for 
data summarization involves multivariate analyses (Yiğit and Mendeş, 2018; Eyduran et al., 2019). Principal component (PC) analysis is an important tool in multivariate methodology used for correlated traits. PC functions mainly to reduce data dimensionality and to explore the relationship between traits (Parés-Casanova et al., 2012; Verma et al., 2015). This technique has been applied in cattle breeding to rank and group bulls (Lopes et al., 2013) and cows efficiently based on similarity. It has also been employed in studying the relationships among the estimated breeding values of various traits (Buzanskas et al., 2013; Boligon et al., 2015) including growth and carcass parameters (Brito et al., 2016).

Although previous attempts have been made to characterize phenotypically the Nigerian cattle (Yakubu et al., 2009; Raji et al., 2014), there is dearth of information on the morphometric differentiation of trade cattle using a classical statistical tool such as multivariate principal component. Therefore, the present study aimed at answering the question whether some trade cattle breeds (Bunaji, Sokoto Gudali, Rahaji and Kuri) in
Nigeria are uniform groups in terms of biometry or demonstrate metric differences in body parts between individuals using principal component analysis.

\section{MATERIALS AND METHODS}

Linear body measurements were taken on a total of 2,120 randomly selected trade cattle of both sexes (1,008 males and 1,112 females) comprising 859 Bunaji, 674 Sokoto Gudali, 409 Rahaji and 178 Kuri. They were transported from the northern parts to the south western part (Bodija International Market, Ibadan, Oyo State) of Nigeria for sale. Bodija Market is a popular open-air market located in Bodija (Figure 1). Ibadan covers a total area of 3,080 square kilometres (1,190 sq mi), the largest in Nigeria (https://en.wikipedia.org/wiki/Ibadan). The Livestock Section of the market is populated by traders of Hausa and Yoruba extractions, which are the two dominant tribes in Nigeria.

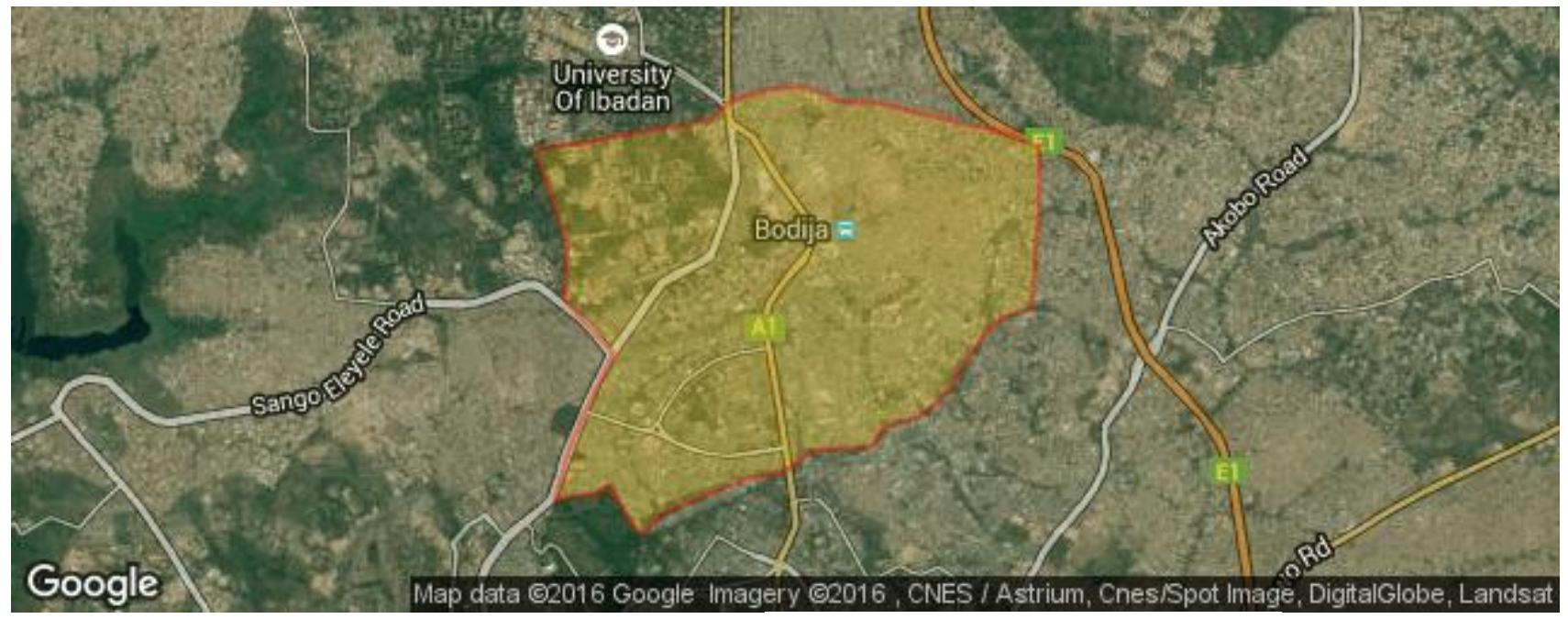

Figure 1: Map of Bodija in Ibadan, Oyo State, Nigeria (Coordinates: $7^{\circ} 25^{\prime} 35^{\prime \prime} \mathrm{N} \quad 3^{\circ} 54^{\prime} 39^{\prime \prime} \mathrm{E}$ )

Source: http://en.wikipedia.org/wiki/Bodija

In the market, the animals were left in the open during the day and in the night. They were fed mainly supplements such as cereal offal and crop residues. The animals were divided into four ages viz., 2-tooth, 4-tooth, 6-tooth and 8-tooth ages, respectively based on the eruption of permanent incisors. They were aged by dentition as indicated below, following the method of Carles and Lampkin (1977):

\begin{tabular}{lc}
\hline Permanent incisors & Age (months) \\
\hline 2-tooth (1 incisor pairs) & $26-27$ \\
4-tooth (2 incisor pairs) & $32-34$ \\
6-tooth (3 incisor pairs) & $38-42$ \\
8-tooth (4 incisor pairs) & $45-50$ \\
\hline
\end{tabular}

Eight morphometric traits were taken on each animal namely height at withers (HTW), height at shoulders (HTS), body length (BDL), shoulder to tail drop (STD), heart girth (HTG), cannon circumference (CNC), ear length (ERL) and tail length (TLL). The anatomical reference points are as described in Brown et al. (1983) and adopted by Raji et al. (2014). The height measurements were done with a calibrated measuring stick graduated in centimeters in $(\mathrm{cm})$ while the girth, circumference and length measurements $(\mathrm{cm})$ were carried out with a flexible tape. Only animals with features that conform to each breed standard were measured. 
Statistical analysis: The analysis of the data was done using the general linear model (GLM) of IBM SPSS (2015) to test the effects of breed, sex and age including their interactions on HTW, HTS, BDL, STD, HTG, CNC, ERL and TLL. The separation of means was done using Duncan's Multiple Range Test (DMRT) at $\alpha=0.05$. The linear additive model employed was:

$\mathrm{Y}_{\mathrm{ijkl}}=\mu+\mathrm{B}_{\mathrm{i}}+\mathrm{S}_{\mathrm{j}}+\mathrm{A}_{\mathrm{k}}+(\mathrm{BS})_{\mathrm{ij}}+(\mathrm{BA})_{\mathrm{ik}}+(\mathrm{SA})_{\mathrm{jk}}+$ $(B S A)_{i j k}+e_{i j k l}$

$\mathrm{Y}_{\mathrm{ijk} \mathrm{l}}=$ observation per individual animal

$\mu=$ population mean

$B_{i}=i^{\text {th }}$ breed fixed effect $(i=$ Bunaji, Sokoto Gudali, Rahaji, Kuri).

$S_{j}=j^{\text {th }}$ sex fixed effect $(j=$ male, female $)$

$A_{k}=k^{\text {th }}$ age fixed effect ( $k=$ 2-tooth, 4-tooth, 6-tooth, 8tooth)

$(B S)_{i j}=$ breed and sex interaction effect

$(\mathrm{BA})_{\mathrm{ik}}=$ breed and age interaction effect

$(\mathrm{SA})_{\mathrm{jk}}=\mathrm{sex}$ and age interaction effect

$(B S A)_{i j k}=$ breed, sex and age interaction effect

$\mathrm{e}_{\mathrm{ijkl}}=$ random error

Pearson's coefficients of correlation were computed for all the traits. The multivariate technique applied was principal component (PC) analysis as earlier described (Yakubu et al., 2009; Vohra et al., 2015). The weights used to create the principal components are the eigenvectors of the characteristic equation:

$\left(\mathrm{S}-\lambda_{\mathrm{i}} \mathrm{I}\right) \mathrm{a}=0$, or

$\left(\mathrm{R}-\lambda_{\mathrm{i}} \mathrm{I}\right) \mathrm{a}=0$

where,

$\mathrm{S}=$ covariance matrix

$\mathrm{R}=$ correlation matrix.

The $\lambda_{i}$ are the eigenvalues, the variances of the components which are obtained by solving $\left|\mathrm{S}-\lambda_{\mathrm{i}} \mathrm{I}\right|=0$ for $\lambda_{\mathrm{i}}$.

Minimum explained variance equal to or less than $70 \%$ criterion for the retention of the main components was adopted as described by Ferreira et al. (2013). The rotation of the factor matrix was done using varimax criterion for easy interpretation of the PC. Antiimage correlations, The Kaiser-Meyer-Olkin measure of sampling adequacy and Bartlett's Test of Sphericity were used to test the reliability of the PC analysis.

\section{RESULTS}

The biometric traits of Kuri cattle were significantly $(\mathrm{P}<0.05)$ higher than those of the three other genetic groups (Table 1). Rahaji had a comparative advantage $(\mathrm{P}<0.05)$ over Sokoto Gudali in all the morphometric traits with the exception of ERL (22.78 \pm 0.20 versus $22.68 \pm 0.12)$. However, Sokoto Gudali was superior $(\mathrm{P}<0.05)$ to Bunaji in all the body parameters estimated.
Sex effect on the morphometric traits was significant $(\mathrm{P}<0.05)$ (Table 2). Male cattle had higher HTW, HTS, BDL, STD, HTG, CNC, ERL and TLL than their female counterparts.

The body measurements were significantly $(\mathrm{P}<0.05)$ influenced by age (Table 3$)$. There was progressive increase in body parameters with age. Although there was growth progression in HTW and HTS, this did not follow a similar trend. Full growth potential of BDL, STD and ERL appeared to have been reached at the 4-tooth age. Same pattern of growth was observed for HTG and $\mathrm{CNC}$, where the peak was obtained at the 8-tooth age. However, there was no definite pattern of growth for TLL.

There were varying interaction effects on the body measurements of cattle (Table 4). Breed * Sex interaction effect $(\mathrm{P}<0.05)$ was on all the linear body traits except CNC and ERL. While Breed ${ }^{*}$ Age and Breed * Sex * Age interaction effects significantly $(\mathrm{P}<0.05)$ influenced all the morphometric traits, only HTS was affected $(\mathrm{P}<0.05)$ by Sex ${ }^{*}$ Age interaction.

Phenotypic correlations among the eight biometric traits are presented in Table 5. Positive and significant $(\mathrm{P}<0.01)$ correlations were recorded for all the linear body measurements. While the highest correlation coefficient was recorded between BDL and STD $(r=$ $0.92)$, the lowest was obtained in HTS and ERL ( $\mathrm{r}=$ $0.13)$.

The low Anti-image correlations showed that true factors existed in the data. This was consolidated by Kaiser-Meyer- Olkin (KMO) measure of sampling adequacy, which revealed the proportion of the variance in the morphometric traits caused by the underlying factor. The KMO value of 0.832 was found to be sufficiently high for all the morphometric traits. Bartlett's Test of Sphericity for the body traits (chi-square $=1.910 \mathrm{E} 4 ; \mathrm{P}<0.01)$ lent credence to the validity of the $\mathrm{PC}$ analysis. A summary of the $\mathrm{PC}$ analysis is shown in Table 6. Based on the criterion of minimum explained variance equal to or less than $70 \%$, two principal components (PC1 and PC2) were retained. The first two components had eigenvalues of 5.564 and 0.906 (90.6\%), respectively and explained about $81 \%$ of the generalized variance.

PC3, PC4, PC5, PC6, PC7 and PC8 were discarded because they had eigenvalues less than 0.7 (Table 7). The associated redundant variables for disposal in order of least importance to explain the total variation in this study were BDL, HTW, HTG, ERL, TLL and CNC.

STD and HTS were the two variables retained in the PC analysis (Table 8). While STD had the highest loading on PC1 (0.874), PC2 was more influenced by HTS (0.956). 
Table 1. Effect of breed on the morphometric traits (Means \pm SE) of Nigerian cattle.

\begin{tabular}{|c|c|c|c|c|}
\hline \multirow{2}{*}{ Traits } & \multicolumn{4}{|c|}{ Breed } \\
\hline & Bunaji & Sokoto Gudali & Rahaji & Kuri \\
\hline HTW & $115.94 \pm 0.38^{\mathrm{d}}$ & $120.49 \pm 0.47^{\mathrm{c}}$ & $125.98 \pm 0.75^{b}$ & $133.47 \pm 0.81^{\mathrm{a}}$ \\
\hline HTS & $46.03 \pm 0.37^{\mathrm{d}}$ & $47.76 \pm 0.46^{\mathrm{c}}$ & $51.49 \pm 0.74^{\mathrm{b}}$ & $60.87 \pm 0.79^{\mathrm{a}}$ \\
\hline $\mathrm{BDL}$ & $157.03 \pm 0.69^{\mathrm{d}}$ & $163.02 \pm 0.85^{\mathrm{c}}$ & $173.58 \pm 1.36^{\mathrm{b}}$ & $188.41 \pm 1.45^{\mathrm{a}}$ \\
\hline STD & $111.00 \pm 0.58^{\mathrm{d}}$ & $115.86 \pm 0.71^{\mathrm{c}}$ & $122.09 \pm 1.14^{\mathrm{b}}$ & $131.50 \pm 1.22^{\mathrm{a}}$ \\
\hline HTG & $139.71 \pm 0.67^{\mathrm{d}}$ & $147.75 \pm 0.83^{c}$ & $151.35 \pm 1.33^{\mathrm{b}}$ & $163.59 \pm 1.43^{\mathrm{a}}$ \\
\hline $\mathrm{CNC}$ & $21.52 \pm 0.10^{\mathrm{d}}$ & $23.01 \pm 0.12^{\mathrm{c}}$ & $23.52 \pm 0.20^{\mathrm{b}}$ & $26.87 \pm 0.21^{\mathrm{a}}$ \\
\hline ERL & $20.69 \pm 0.10^{c}$ & $22.68 \pm 0.12^{\mathrm{b}}$ & $22.78 \pm 0.20^{\mathrm{b}}$ & $21.27 \pm 0.21^{\mathrm{a}}$ \\
\hline TLL & $91.28 \pm 0.47^{\mathrm{d}}$ & $94.65 \pm 0.58^{c}$ & $100.90 \pm 0.93^{b}$ & $108.98 \pm 0.99^{\mathrm{a}}$ \\
\hline
\end{tabular}

$\mathrm{HTW}=$ height at withers; HTS=height at shoulders, $\mathrm{BDL}=$ body length; $\mathrm{STD}=$ shoulder to tail drop, $\mathrm{HTG}=$ heart girth, $\mathrm{CNC}=$ cannon circumference, $\mathrm{ERL}=$ ear length; $\mathrm{TLL}=$ tail length, $\mathrm{SE}=$ standard error

Means in the same row with different superscripts are significantly different $(\mathrm{P}<0.05)$

Table 2. Effect of sex on the morphometric traits (Means \pm SE) of Nigerian cattle.

\begin{tabular}{ccc}
\hline Traits & Sex & Male \\
\cline { 2 - 3 } & $121.826 \pm 0.45^{\mathrm{b}}$ & $126.12 \pm 0.45^{\mathrm{a}}$ \\
HTW & $49.49 \pm 0.44^{\mathrm{b}}$ & $53.58 \pm 0.43^{\mathrm{a}}$ \\
HTS & $166.26 \pm 0.81^{\mathrm{b}}$ & $174.76 \pm 0.80^{\mathrm{a}}$ \\
STD & $117.39 \pm 0.68^{\mathrm{b}}$ & $122.84 \pm 0.67^{\mathrm{a}}$ \\
HTG & $146.21 \pm 0.79^{\mathrm{b}}$ & $154.99 \pm 0.78^{\mathrm{a}}$ \\
CNC & $23.33 \pm 0.12^{\mathrm{b}}$ & $24.12 \pm 0.12^{\mathrm{a}}$ \\
ERL & $21.51 \pm 0.12^{\mathrm{b}}$ & $22.20 \pm 0.12^{\mathrm{a}}$ \\
TLL & $96.97 \pm 0.55^{\mathrm{b}}$ & $100.93 \pm 0.55^{\mathrm{a}}$ \\
\hline
\end{tabular}

$\mathrm{SE}=$ standard error

Means in the same row with different superscripts are significantly different $(\mathrm{P}<0.05)$

Table 3. Effect of age on the morphometric traits (Means \pm SE) of Nigerian cattle.

\begin{tabular}{ccccc}
\hline \multirow{2}{*}{ Traits } & \multicolumn{3}{c}{ Age } \\
\cline { 2 - 5 } & 2-tooth & 4-tooth & 6-tooth & 8-tooth \\
\hline HTW & $120.76 \pm 0.70^{\mathrm{c}}$ & $124.44 \pm 0.66^{\mathrm{b}}$ & $124.17 \pm 0.76^{\mathrm{b}}$ & $126.52 \pm 0.31^{\mathrm{a}}$ \\
HTS & $49.92 \pm 0.68^{\mathrm{c}}$ & $49.92 \pm 0.64^{\mathrm{c}}$ & $52.02 \pm 0.74^{\mathrm{b}}$ & $54.28 \pm 0.30^{\mathrm{a}}$ \\
BDL & $164.62 \pm 1.25^{\mathrm{b}}$ & $170.89 \pm 1.18^{\mathrm{a}}$ & $173.52 \pm 1.37^{\mathrm{a}}$ & $173.01 \pm 0.56^{\mathrm{a}}$ \\
STD & $116.21 \pm 1.05^{\mathrm{b}}$ & $120.43 \pm 1.00^{\mathrm{a}}$ & $121.89 \pm 1.15^{\mathrm{a}}$ & $121.93 \pm 0.47^{\mathrm{a}}$ \\
HTG & $146.16 \pm 1.23^{\mathrm{c}}$ & $151.31 \pm 1.16^{\mathrm{b}}$ & $150.31 \pm 1.34^{\mathrm{b}}$ & $154.63 \pm 0.55^{\mathrm{a}}$ \\
CNC & $23.01 \pm 0.18^{\mathrm{c}}$ & $23.90 \pm 0.17^{\mathrm{b}}$ & $23.64 \pm 0.20^{\mathrm{b}}$ & $24.36 \pm 0.08^{\mathrm{a}}$ \\
ERL & $21.38 \pm 0.18^{\mathrm{b}}$ & $21.88 \pm 0.17^{\mathrm{a}}$ & $21.98 \pm 0.20^{\mathrm{a}}$ & $22.18 \pm 0.08^{\mathrm{a}}$ \\
TLL & $96.45 \pm 0.86^{\mathrm{c}}$ & $99.70 \pm 0.81^{\mathrm{ab}}$ & $98.62 \pm 0.94^{\mathrm{bc}}$ & $101.04 \pm 0.38^{\mathrm{a}}$ \\
\hline
\end{tabular}

$\mathrm{SE}=$ standard error

Means in the same row with different superscripts are significantly different $(\mathrm{P}<0.05)$

Table 4. Analysis of variance showing the interaction effect of breed, sex and age on the morphometric traits of Nigerian cattle.

\begin{tabular}{|c|c|c|c|c|c|c|c|c|c|}
\hline \multirow{2}{*}{$\begin{array}{l}\text { Source } \\
\text { variation }\end{array}$} & \multirow[t]{2}{*}{ DF } & \multicolumn{8}{|c|}{ Mean squares and level of significance } \\
\hline & & HTW & HTS & BDL & STD & HTG & CNC & ERL & TLL \\
\hline Breed $^{*}$ Sex & 3 & $579.52^{* *}$ & $650.78^{* *}$ & $2881.35^{* *}$ & $2435.35^{* *}$ & $1519.49^{* *}$ & $3.83^{\text {ns }}$ & $3.80^{\mathrm{ns}}$ & $621.96^{* *}$ \\
\hline Breed ${ }^{*}$ Age & 9 & $746.44^{* *}$ & $990.27^{* *}$ & $2869.80^{* *}$ & $2928.10^{* *}$ & $1583.45^{* *}$ & $24.83^{* *}$ & $31.42^{* *}$ & $722.74^{* *}$ \\
\hline Sex ${ }^{*}$ Age & 3 & $88.67^{\mathrm{ns}}$ & $539.00^{* *}$ & $316.37^{\mathrm{ns}}$ & $222.06^{\mathrm{ns}}$ & $282.35^{\mathrm{ns}}$ & $12.87^{\mathrm{ns}}$ & $2.42^{\text {ns }}$ & $92.42^{\mathrm{ns}}$ \\
\hline Breed ${ }^{*}$ Sex ${ }^{*}$ Age & 9 & $403.92^{* *}$ & $274.47^{* *}$ & $690.80^{* *}$ & $648.19^{* *}$ & $869.10^{* *}$ & $22.89^{* *}$ & $16.50^{* *}$ & $385.54^{* *}$ \\
\hline Residual & 2008 & 80.38 & 75.47 & 257.86 & 182.27 & 247.37 & 5.39 & 5.44 & 120.41 \\
\hline
\end{tabular}

$\mathrm{DF}=$ degree of freedom; ${ }^{* *}$ Significant at $\mathrm{P}<0.01 ;{ }^{\text {ns }}$ Non-significant 
Table 5. Phenotypic correlations of the morphometric traits of Nigerian cattle**

\begin{tabular}{|c|c|c|c|c|c|c|c|c|}
\hline Trait & HTW & HTS & BDL & STD & HTG & CNC & ERL & TLL \\
\hline HTW & & 0.52 & 0.88 & 0.85 & 0.91 & 0.80 & 0.53 & 0.76 \\
\hline HTS & & & 0.62 & 0.35 & 0.51 & 0.51 & 0.13 & 0.34 \\
\hline BDL & & & & 0.92 & 0.85 & 0.73 & 0.47 & 0.72 \\
\hline STD & & & & & 0.81 & 0.69 & 0.49 & 0.72 \\
\hline HTG & & & & & & 0.82 & 0.48 & 0.72 \\
\hline $\mathrm{CNC}$ & & & & & & & 0.43 & 0.65 \\
\hline ERL & & & & & & & & 0.40 \\
\hline
\end{tabular}

${ }^{* *}$ Significant at $\mathrm{P}<0.01$ for all correlation coefficients.

Table 6. Principal components, eigenvalues and percentage of variance explained by components (\% VCP).

\begin{tabular}{lccc}
\hline Principal components & Eigenvalues & \% (VCP) & \% (VCP) cumulative \\
\hline 1 & 5.564 & 69.544 & 69.544 \\
2 & 0.906 & 11.327 & 80.871 \\
3 & 0.584 & 7.306 & 88.177 \\
4 & 0.360 & 4.504 & 92.681 \\
5 & 0.323 & 4.041 & 96.721 \\
6 & 0.148 & 1.854 & 98.575 \\
7 & 0.087 & 1.085 & 99.660 \\
8 & 0.027 & 0.340 & 100.000 \\
\hline
\end{tabular}

Table 7. Weighting coefficients of morphological traits of cattle discarded with the principal components.

\begin{tabular}{lcccccc}
\hline Variables & \multicolumn{5}{c}{ Principal Components } \\
\cline { 2 - 6 } & $\mathbf{3}$ & $\mathbf{4}$ & $\mathbf{5}$ & $\mathbf{6}$ & $\mathbf{7}$ & $\mathbf{8}$ \\
\hline HTW & 0.393 & 0.369 & 0.270 & 0.220 & 0.411 & 0.005 \\
HTS & 0.182 & 0.101 & 0.021 & 0.069 & 0.042 & 0.001 \\
BDL & 0.258 & 0.298 & 0.216 & 0.094 & 0.061 & 0.153 \\
STD & 0.258 & 0.298 & 0.228 & 0.102 & 0.037 & -0.083 \\
HTG & 0.435 & 0.310 & 0.217 & 0.520 & 0.108 & 0.005 \\
CNC & 0.823 & 0.271 & 0.189 & 0.111 & 0.059 & 0.006 \\
ERL & 0.140 & 0.132 & 0.954 & 0.062 & 0.041 & 0.003 \\
TLL & 0.250 & 0.857 & 0.164 & 0.099 & 0.058 & 0.005 \\
\hline
\end{tabular}

Table 8. Weighting coefficients of morphological traits of cattle retained with the principal components.

\begin{tabular}{lcc}
\hline & \multicolumn{3}{c}{ Principal Components } \\
\cline { 2 - 3 } Variable & $\mathbf{1}$ & $\mathbf{2}$ \\
\hline HTW & 0.588 & 0.269 \\
HTS & 0.189 & $\mathbf{0 . 9 5 6}$ \\
BDL & 0.778 & 0.369 \\
STD & $\mathbf{0 . 8 7 4}$ & 0.103 \\
HTG & 0.565 & 0.258 \\
CNC & 0.355 & 0.268 \\
ERL & 0.217 & 0.028 \\
TLL & 0.381 & 0.129 \\
\hline
\end{tabular}

\section{DISCUSSION}

The present findings revealed that Bunaji appeared to be the smallest, while Kuri exhibited more robustness among all the cattle breeds investigated. The values obtained for Kuri cattle in this study are close to the range $132.04+1.64-132.51+1.54$ (height at withers), $160.88+2.01-166.91+2.21$ (heart girth), 182.77+2.89$187.07+2.00$ (body length), 133.24+1.74-133.51+1.54 (shoulder to tail drop), 21.07+0.44-21.93+0.49 (ear 
length) and 109.22+1.83-111.48+1.82 (tail length) reported by Raji et al. (2014) for the same breed. Breed influence on body traits has also been reported by Boujenane (2015). The present information may identify breeds potentially useful in breeding and conservation programmes in terms of meat production and may aid in understanding domestication in Nigerian cattle. According to Dossa et al. (2007), rapid selection of large size individuals for the establishment of elite flocks in the field may be possible using biometric measurements such as height at withers, body length and chest girth. In a similar fashion, Gizaw et al. (2007) reported that morphological description is an essential component of breed characterization for physical identification, description, and recognition of a breed, and also for livestock breeds classification into broad categories.

The superiority of the male over the female is as a result of sexual dimorphism (SD) (Yakubu and Akinyemi, 2010). Sex differences in most morphometric traits studied were also observed in cattle by Taiwo et al. (2010) and Yakubu et al. (2018). The higher morphometric measurements of male animals in this study is congruous to Polak and Frynta (2010) sexual selection hypothesis, providing the most intuitive explanation for male-larger sexual size dimorphism in cattle, whereby a male combat is a regular part of malemale competition for promiscuous oestrous females living frequently in mixed herds. SD may also be attributed to the delay in sexual maturation and males' prolonged growth.

The conformation traits of animals are greatly influenced by age. There were differential growth rates by each biometric trait at different age groups in the present study. Certain body parameters such as BDL, STD and ERL were mature early and also ceased growing before others. This, according to Yakubu (2011b), indicated that the essential body evolution of mammalian animals occurred before the maturity stage and there is a general pattern of growth till maturity stage. This was buttressed by the submission of Blackmore et al. (1995) that in skeletal development, there is faster growth in length than in width and circumference.

The four genotypes under the two sexes and four ages investigated were separately ranked in the present study. Breed ${ }^{*}$ sex interaction showed that the breeds performed differently in both sexes for the traits that were influenced. The results obtained for interaction of breed ${ }^{*}$ age suggest the sensitivity of the expressed forms of the four breeds to age differences while sex ${ }^{*}$ age indicates that the performance of male and female cattle is different for HTS under the four ages investigated. Breed * age ${ }^{*}$ sex interaction indicates that the performance of Bunaji, Sokoto Gudali, Rahaji and Kuri cattle may be different for male and female under 2 teeth, 4 teeth, 6 teeth and 8 teeth ages, respectively. Zulu (2008) reported breed ${ }^{*}$ sex interaction effect on WH and BDL in Zambian native cattle breeds.

The body parameters, as observed in this study, were associated with one another. Similar estimates of correlation were reported in cattle by Raji et al. (2014). The strong relationship existing between most of the body parameters may be useful for selection purpose, considering similar gene action of positively correlated traits. This may be utilized in the genetic improvement of the indigenous stock especially in the rural areas where resources for large scale breeding programme are scarce.

Variation in breeds' characteristics permits animal identification within the breed standards. Size and conformation are parameters of high priority to most cattle herders and are strong selection presumably in most breeds. The PC analytic tool combines the morphometric variables to produce indices or components that are uncorrelated (Mavule et al., 2013). The importance of PC analysis in the present study was evident in the reduction of large number of explanatory variables (biometric traits) into two components (PC1 and PC2) that were able to describe size and shape better. This is in conformity with the submissions of Khargharia et al. (2015) and Shah et al. (2018). Since correlations between principal components are zero, the selection of animals for any principal component will produce independent response in terms of other principal components (Pinto et al., 2006).

The two selected variables (STD and HTS) in the present study showed lower simple correlation (Pearson's correlation) with each other, hence they are non-redundant. In this wise, the use of STD and HTS could be combined with other parameters of economic importance in classic evaluation of animals for characterization, racial discrimination, breeding and selection purposes. Height is a veritable trait used in determining the proper size of the animal, and its consistency with the breed standards presents high genetic correlations between growth traits (Pereira et al., 2010). Similarly, Mavule et al. (2013) reported that breeders could improve body shape to increase meat production traits and maintain an animal's body size suitable for walking longer distances and survival in harsh environmental conditions. Similarly, Verma et al. (2015) reported that PC could be used in breeding programmes with sufficient reduction in the number of recorded linear type traits to explain the body conformation of animals. The use of records on only STD and HTS corresponding to two PCs, instead of the original eight body parameters will ultimately lead to a reduction in the costs of labour and other resources used to evaluate animals. Similarly, Parés-Casanova et al.(2013) reported that first two PCs could be exploited in the evaluation and comparison of cattle; thus, it could provide an opportunity for the selection of animals based on a small group of traits rather than on isolated traits. 
Conclusion: Kuri cattle had significantly higher morphometric variables compared to other breeds such as Rahaji, Sokoto Gudali and Bunaji. Sex and age also influenced all the body measurements while there were varying breed and sex, breed and age, sex and age and breed and sex and age interaction effects on the body parameters. The positive and significant correlations among different biometric traits suggested high predictability among the different traits, and also made them amenable for PC analysis. Two parameters (STD and HTS) which recorded the single highest loading on PC1 and PC2, respectively were sufficient to distinguish between the breeds. The present information may be exploited in phenotypic selection as a means to elucidate body conformation; and when complemented with molecular characterization, could be useful in future efforts geared towards conserving the indigenous cattle.

Authors' contributions: AY and AA conceived the study. AOR was instrumental to data collection. AY, AA and SOO did the statistical analysis. All authors wrote and proofread the manuscript.

Conflict of interest: The authors declare that there exists no conflict of interest with regard to the manuscript

\section{REFERENCES}

Aksoy, A., Y. E Ertürk, E. Eyduran and M.M. Tariq (2018). Comparing predictive performances of MARS and CHAID algorithms for defining factors affecting final fattening live weight in cultural beef cattle enterprises. Pakist. J. Zool. 50(6): 2279-2286.

Blackmore, D.W., L.D. McGulliard and J.L. Lush (1995). Growth and development of Aberdeen Angus cattle. Arkansas Agric. Experiment Station Bull. 571: 10-10.

Boligon, A.A., F.A. Silveira, D.D. Silveira, N.J. Dionello, M.L. Jr Santana, A.B. Bignardi and F.R. Souza (2015). Reduced-rank models of growth and reproductive traits in Nelore cattle. Theriogenology, 83(8): 1338-1343.

Boujenan, I. (2015). Multivariate characterisation of Oulmes-Zaer and Tidili cattle using the morphological traits. Iranian J. Appl. Anim. Sci. 5(2): 293-299.

Brito, L.F., M.C. da Silva, C.U. Magnabosco, M. Goncalves Narciso and R.D. Sainz (2016). Selection indices and multivariate analysis show similar results in the evaluation of growth and carcass traits in beef cattle. PLoS ONE, 11(1): e0147180. doi:10.1371/journal.pone.0147180

Brown, C.J., A.H. Brown, Jr. and Z. Johnson (1983). Studies of body dimensions of beef cattle. Ark. Agr. Expt. Sta. Bulletin. P. 863.
Buzanskas, M.E., R.P. Savegnago, D. Grossi, G.C. Venturini, S. Queiroz and L.O.C. Silva et al. (2013). Genetic parameter estimates and principal component analysis of breeding values of reproduction and growth traits in female Canchim cattle. Reprod. Fertil. Dev. 25: 775781.

Carles, A.B. and K.M. Lampkin (1977). Studies of the permanent incisor eruption, and body development, of the large East African Zebu (Boran): 1. The ages at first appearance of the incisors, lengths of the incisor eruption period, and source of variation. J. Agric. Sci. (UK) 88: 341-360.

Dietl, G., S. Hoffmann and N. Reinsch (2005). Impact of trainer and judges in the mare performances test of warm blood horses. Arch. Tierz Dummerstorf 48:113-120.

Dossa, L.H., C. Wollny and M. Gauly (2007). Spatial variation in goat populations fromBenin as revealed by multivariate analysis of morphological traits. Small Rum. Res. 73:150159.

Eyduran, E., M. Akin and S.P. Eyduran (2019). Application of multivariate adaptive regression splines through $R$ Software. Nobel Academic Publishing, Ankara

Ferreira, T.A., I.G. Pereira, A.M.G. Gouveia, A.V. Pires, O. Facó, C.T. Meira, I.F.F. Garcia and M.P.S.L.M. Guimarães (2013). Morphological traits and type of dairy goats registered in Brazil from 1976 to 2009. R. Bras. Zootec. 42(12): 857-861.

Gibbs, R. A., J.F. Taylor, C.P. Van Tassell, W. Barendse, K.A. Eversole, C.A. Gill, R.D. Green D.L. Hamernik, S.M. Kappes, S. Lien, L.K. Matukumalli, J.C. McEwan, L.V. Nazareth, R.D. Schnabel, G.M. Weinstock, D.A. Wheeler, P. Ajmone-Marsan, P.J. Boettcher, A.R. Caetano, K.G. Dodds (2009). Genome-wide survey of SNP variation uncovers the genetic structure of cattle breeds. Sci. 324(5926: 528 532. https://doi.org/10.1126/science.1167936.

Gizaw, S., J.A.M. van Arendonk, H. Komen, J.J. Windig and O. Hanotte (2007). Population structure, genetic variation and morphological diversity in indigenous sheep of Ethiopia. Anim. Genet. 38:621-628.

Houessou, S.O., L.H. Dossa, R.V.C .Diogo, M.C. Ahozonlin, M. Dahouda and E. Schlecht (2019). Confronting pastoralists' knowledge of cattle breeds raised in the extensive production systems of Benin with multivariate analyses of morphological traits. PLoS ONE, 14(9): e0222756.

https://doi.org/10.1371/journal.pone.0222756 
IBM Corp. Released 2015. IBM SPSS Statistics for Windows, Version 542 23.0. Armonk, NY: IBM Corp.

Kern, E. L. J. A. Cobuci, C. N. Costa and C. M. M. Pimentel (2014). Factor analysis of linear type traits and their relation with longevity in Brazilian Holstein cattle. Asian-Australas J Anim Sci., 27(6): 784-790. doi: 10.5713/ajas.2013.13817

Khargharia, G., G. Kadirvel, S. Kumar, S. Doley, P.K. Bharti and M. Das (2015). Principal component analysis of morphological traits of Assam Hill goat in Eastern Himalayan India. J. Anim. Plant Sci. 25(5): 1251-1258.

Köhler-Rollefson, I., 2000. Management of animal genetic diversity at community level. Management Agrobiodiversity in Rural areas. Deuteche Gesellschaft für Technishe Zusammenarbeit (GTZ) GmbH. Eschborn. $\mathrm{ftp}: / / \mathrm{ftp}$.fao.org/docrep/nonfao/lead/x6103e/x6103e00.pdf.

Ladyka, V.I., L.M. Khmelnychyi, S.L. Khmelnychyi, A.M. Salohub and V.V. Vechorka (2020). Association between linear traits of legs and longevity of Ukrainian Brown dairy cows. J. Anim. Plant Sci. 30: 312-318.

Lopes, F.B., C.U. Magnabosco, M.M. Mamede, M.C. da Silva, E.S. Myiage and F. Paulini et al. (2013). Multivariate approach for young bull selection from a performance test using multiple traits of economic importance. Trop. Anim. Health Prod. 45: 1375-1381.

Mavule, B.S., V. Muchenje, C.C. Bezuidenhout and N.W. Kunene (2013). Morphological structure of Zulu sheep based on principal component analysis of body measurements. Small Rumin. Res. 111: 23-30.

Mustafa, H., N. Ahmad, H.J. Heather, K. Eui-soo, W.A. Khan, A. Ajmal, K. Javed, T.N. Pasha, A. Ali, J.J. Kim and T.S. Sonstegard (2018). Whole genome study of linkage disequilibrium in Sahiwal cattle. S. Afr. J. Anim. Sci. 48(2): 253260.

Mwacharo, J.M., A.M. Okeyo, G.K. Kamande and J.E.O. Rege (2006). The small East African shorthorn zebu cows in Kenya. 1: Linear body measurements. Trop. Anim. Health Prod. 38: 6576.

Nyamushamba, G.B., C. Mapiye, O. Tada, T.E. Haliman and V. Muchenje (2017). Conservation of indigenous cattle genetic resources in Southern Africa's smallholder areas: Turning threats into opportunities. Asian-Australas. J. Anim. Sci. 30(5): 603-621.

Parés-Casanova, P.M., I. Sinfreu and D. Villalba (2012). Principal component analysis of cephalic morphology to classify some Pyrenean cattle. Anim. Genet. Res. 50: 59-64.

Parés-Casanova, P.M., I. Sinfreu and D. Villalba (2013). Application of varimax rotated principal component analysis in quantifying some zoometrical traits of a relict cow. Korean J. Vet. Res. 53(1): 7-10.

Pereira, M.C., M.J. Yokoo, A.B. Bignardi, J.C. Sesana and L.G. Albuquerque (2010). Hip height and its relationships with reproductive and growth traits in Nelore cattle. Pesqi. Agropecu. Bras. 45: 613-620.

Pinto, L.F.B., I.U. Packer, C.M.R. De Melo, M.C. Ledur and L.L. Coutinho (2006). Principal components analysis applied to performance and carcass traits in the chicken. Anim. Res. 55: 419-425.

Polak, J. and D. Frynta (2010). Patterns of sexual size dimorphism in cattle breeds support Rensch's rule. Evol. Ecol. 24: 1255-1266.

Raji, A.O., F.I. Abattor and O. Olutogun (2014). Kuri cattle of the Lake Chad region: Relationship between age, sex and body dimensions. I.J.S.N. 5 (1): 87-90.

Rege, J.E.O., K. Marshall, A. Notenbaert, J. Ojango and A.O. Mwai (2011). Pro-poor animal improvement and breeding-What can science do? Livest. Sci. 136(1): 15-28.

Schwabe, A.E. and S.J.G. Hall (1989). Dystocia in nine British breeds of cattle and its relationships to the dimensions of the dam and calf. The Vet. Record 125: 636-639.

Shah, W.A., N. Ahmad, M. Saadullah, M. E. Babar, T.N. Pasha, S. Ahmad, A. Ali, Nasrullah, M. Z. Farooq and A.H. Saleem (2018). Multivariate analysis of biometeric traits in Cholistani cattle. J. Anim. Plant Sci. 28(3): 940-944.

Sobczuk, D. and M. Komosa (2012. Morphological differentiation of Polish Arabian horses Multivariate analysis. Bull. Vet. Inst. Pulawy 56: 623-629.

Taiwo, B.B.A., Olaniran, O.D.D. and F.A. Aluko (2010). Breed and environmental factors affecting body measurements of beef cattle in Yewa, Nigeria. Agric. J. 5 (3): 211-214

Tolenkhomba, T.C., S.N. Singh and D.C. Konsam (2013). Principal component analysis of body measurements of bulls of local cattle of Manipur, India. Indian J. Anim. Sci. 83(3): 28184.

Verma, D., V. Sankhyan, S. Katoch and Y.P. Thakur (2015). Principal component analysis of biometric traits to reveal body confirmation in local hill cattle of Himalayan state of Himachal Pradesh, India. Vet. World 8(12): 1453-1457.

Vohra, V., S.K. Niranjan, A.K. Mishra, V. Jamuna, A. Chopra, N. Sharma and D.K. Jeong (2015). 
Phenotypic characterization and multivariate analysis to explain body conformation in lesser known Buffalo (Bubalus bubalis) from North India. Asian Australas. J. Anim. Sci. 28(3): 311317.

Yakubu, A. and M.O. Akinyemi (2010). An evaluation of sexual size dimorphism in Uda sheep using multifactorial discriminant analysis. Acta Agric. Scand. A- Anim. Sci. 60(2): 74-78.

Yakubu, A., A.E. Salako and A-R. Abdullah (2011b). Varimax rotated principal component analysis of the zoometrical traits of Uda sheep. Arch. de Zootec. 60(231): 813-816.

Yakubu, A., A.V. Hingir and A-R. Abdullah (2018). Multivariate analysis of sexual dimorphism in the morphometric traits of Muturu cattle in north central Nigeria. Nig. J. Genet. 32: 8-15.
Yakubu, A., D.M. Ogah and K.O. Idahor (2009). Principal component of the morphstructural indices of White Fulani cattle. Trakia J. Sci. 7 (2): 67-73.

Yakubu. A., Salako, A.E. and I.G. Imumorin (2011a). Comparative multivariate analysis of biometric traits of West African Dwarf and Red Sokoto goats. Trop. Anim. Health Prod. 43: 561-566.

Yiğit, S. and M. Mendeș (2018). Multivariate perspective for investigating relations among some behavioral traits and feed programs. J. Anim. Plant Sci. 24(4): 1186-1188.

Zulu, D.N. (2008). Genetic Characterization of Zambian native cattle breeds. A Thesis submitted to the Faculty of the Virginia Polytechnic Institute and State University in partial fulfillment of the requirements for the degree of Master of Science in Animal and Poultry Sciences. 61pp. 